\title{
Acute and Subacute Ischemic Stroke-A Review of Temperature, Blood Pressure and Glycemic Management
}

\author{
Shannon Hextrum and Barak Bar \\ Department of Neurology, Loyola University Chicago, US
}

DOl: https://doi.org/10.17925/USN.2016.12.02.105

$\mathrm{T}$ he treatment of ischemic stroke is often divided between acute interventions (endovascular therapy, intravenous tissue plasminogen activator [IV tPA]) and long-term secondary prevention (modifying risk factors, antithrombotic therapy, etc.). There is great variability between practitioners in the medical management of stroke during hospitalization, in part because of confusing and contradictory results in the literature. Temperature management and therapeutic hypothermia is discussed in this review. In regards to blood pressure targets, while permissive hypertension is often recognized as a beneficial strategy in acute stroke, blood pressure reduction is essential for secondary stroke prevention. We review the literature regarding optimal timing of different blood pressure goals. Finally, the limited literature regarding glycemic control in ischemic stroke patients is discussed.

\section{Keywords}

Ischemic stroke, hyperthermia, therapeutic hypothermia, hypertension, permissive hypertension, hyperglycemia, hypoglycemia

Disclosure: Shannon Hextrum, Barak Bar have nothing to disclose in relation to this article. No funding was received in the publication of this article.

Compliance with Ethics: This article involves a review of the literature and did not involve any studies with human or animal subjects performed by any of the authors.

open Access: This article is published under the Creative Commons Attribution Noncommercial License, which permits any non-commercial use, distribution, adaptation and reproduction provided the original author(s) and source are given appropriate credit.

Received: July 16, 2016

Accepted: August 31, 2016

Citation: US Neurology, 2016;12(2):105-9

Corresponding Author: Shannon Hextrum, Department of Neurology, Loyola University Chicago, Stritch School of Medicine, 2160 S. First Avenue, Maywood, Illinois, US, 60153. E·Shannon.hextrum@lumc.ed
Currently there is a tremendous amount of research interest in acute reperfusion therapy for patients suffering from acute ischemic stroke. However, other aspects of patient care in acute and subacute stroke are typically considered routine and thus have received less attention. The present guidelines emphasize medical management during the first 24-48 hours after infarction, but do little to address the management in the remainder of hospitalization. In this review article, we will discuss temperature management, blood pressure management, and glycemic control in patients with subacute ischemic stroke. Timely randomized controlled trials (RCTS) have attempted to address these topics, and in this review, we critically examine and summarize the evidence to date. We chose to focus on the management of temperature during the entire inpatient hospital stay. In regards to blood pressure, we focused on the inpatient management without discussing long-term outpatient management, and lastly for glycemic control, we focused on the acute to subacute management.

\section{Temperature management in acute ischemic stroke}

The issue of temperature management following acute ischemic stroke is complex and evolving Hyperthermia is a frequent complication in up to $50 \%$ of patients with acute ischemic stroke. Recently, the European Stroke Organization (ESO) published evidence-based guidelines in 2015 for the management of temperature in patients with acute ischemic stroke. ${ }^{2}$ According to these guidelines, in patients with acute ischemic stroke and hyperthermia, no recommendations were made for treating hyperthermia as a means to improve functional outcome and/or survival. ${ }^{2}$ This conclusion was reached after finding low quality of evidence with only two RCTs with a total of 42 patients to analyze this question.

It is possible that therapeutic normothermia or the avoidance of hyperthermia provides the bulk of the benefit seen in prior studies of cardiac arrest survivors. ${ }^{3,4}$ However, the ESO guidelines state that in patients with acute ischemic stroke and normothermia, there is no recommended routine prevention of hyperthermia with antipyretics as a means to improve functional outcome and/or survival. The quality of evidence is moderate, and the strength of this recommendation is weak. ${ }^{2}$

Following two previous clinical trials s.4 $^{3,4}$ showing a significant benefit of mild therapeutic hypothermia after out-of-hospital cardiac arrest, one can make a plausible argument that the benefit seen for cardiac arrest patients may also apply to acute ischemic stroke patients. In both scenarios there is ischemia to brain parenchyma secondary to hypoperfusion. However, one must be aware that controversy exists regarding the potential benefit of therapeutic hypothermia for cardiac arrest, especially given the results of the landmark targeted temperature management (TTM) trial. ${ }^{5}$ In this 
large multicenter, international trial including 939 patients there was no benefit conferred to patients treated with hypothermia at a targeted temperature of $33^{\circ} \mathrm{C}$ compared with a targeted temperature of $36^{\circ} \mathrm{C}$.

Keeping this in mind, there are currently several human clinical trials attempting to answer the question of whether therapeutic hypothermia improves clinical outcome in acute ischemic stroke patients. One of these is EuroHYP-16, which is a phase III randomized open label trial to assess the effect of 24 hours of mild hypothermia (target body temperature $34-35^{\circ} \mathrm{C}$ ) on 90 day modified Rankin Scale (mRS) score. The goal of the trial is to enroll 1500 patients. Another important trial is the ICTuS 2/3 study. In this randomized clinical trial, of which 200 patients out of 400 were enrolled, patients had endovascular cooling catheters placed after receiving intravenous thrombolysis with the goal of reaching a target temperature of $33^{\circ} \mathrm{C}$ within 6 hours of stroke onset, and maintaining that temperature for 24 hours. The trial was stopped early for unclear reasons, and the results are yet to be published. It remains to be seen if this new resurgence in research interest for the use of therapeutic hypothermia for neuroprotection in acute ischemic stroke patients will be fruitful. Presently, the ESO guidelines state that in patients with acute ischemic stroke, induction of hypothermia is not recommended as a means to improve functional outcome and/or survival with a very low quality of evidence and a weak recommendation.

The results of the previously mentioned clinical trials will surely provide us with guidance on therapeutic hypothermia for acute ischemic stroke patients and likely raise more questions as well. Clinical experience has clearly demonstrated that there are patients who have a clinical deterioration with fever and others that do not. Which specific factors determine the response to fever in ischemic stroke patients remains unknown. Perhaps the future will provide us with better knowledge of the specific factors involved which will allow us to provide more tailored therapies for these patients. Until there is convincing evidence for therapeutic hypothermia in ischemic stroke it is advisable to avoid this approach given the inherent risks of hypothermia without any proven benefit at this time. Finally, it appears reasonable to avoid hyperthermia and to aim for a goal of normothermia given that the risks of this approach are minimal and potentially beneficial.

\section{Blood pressure management}

The management of blood pressure in the setting of acute ischemic infarction is complicated by two opposing concepts: one maintains that acute hypertension has been associated with poor outcomes, the other states that rapid blood pressure reduction may limit the recovery of tissue penumbra. ${ }^{8-10}$ Current American Heart Association/American Stroke Association (AHA/ASA) guidelines recommend treatment of blood pressure above 220 systolic and/or 120 diastolic. ${ }^{11}$ However, controversy lies in the management of more modest pressure elevations (i.e. 150-180s systolic), and this is especially true in the timeframe beyond 24-48 hours post-infarction.

The prospective COSSACS trial ${ }^{12}$ randomized 763 patients to either resume their outpatient anti-hypertensive regimen or stop for 2 weeks after ischemic or hemorrhagic infarction. At both 2- week and 6-month trial endpoints, there was no significant difference between groups in measures of dependency (characterized by mRS of $>3$ ), mortality, or additional cerebrovascular events. ${ }^{12}$
The cosSACs trial lacked sufficient statistical power to detect correlation between blood pressure reduction and improved patient outcomes. However, neutral results were also seen in the larger clinical trial CATIS, which included 4071 ischemic stroke patients. ${ }^{13}$ Eligible participants had initial systolic blood pressure between 140 and $220 \mathrm{~mm} \mathrm{Hg}$. The treatment group received antihypertensive therapy to reduce systolic blood pressure by $10 \%$ to $25 \%$ in the first 24 hours after group assignment, followed by a target blood pressure of $<140 / 90$, which was achieved at day five. Control subjects received no antihypertensive agents during hospitalization, with an average length of stay of 13 days. Outcome measures were death or major disability (mRS $\geq 3$ ) at both 14 days (or hospital discharge) and at 3 months. Results indicated no significant differences between groups, with the exception of patients started on antihypertensive therapy greater than 24 hours after symptom onset, who demonstrated improved functional outcome at 3 months. ${ }^{13}$ This provides clinical evidence to support the concept of allowing permissive hypertension for the first 24 hours after infarction.

The strengths of CATIS include a large sample population, minimal loss to follow-up, categorization of ischemic stroke etiology, and exclusion of hemorrhagic strokes. Nevertheless, the selection criteria excluded all patients with atrial fibrillation and overrepresented thrombotic stroke. The average National Institutes of Health Stroke Scale (NIHSS) score of participants was only 4 (with an interquartile range of 2-7 in the treatment arm and 3-8 in the control), signifying a selection bias towards less severe strokes, which could account for the apparently blunted effects of aggressive blood pressure management due to a ceiling effect.

The ENOS trial included 4011 patients with greater symptom burden than CATIS, requiring the presence of a motor deficit and averaging an estimated NIHSS score of 11 for each group (Table 1).14 This was a multi-national, parallel-group trial, in which patients were allocated to receive transdermal glyceryl trinitrate or not, and patients already taking antihypertensives (in either treatment or control) were further randomized to continue or stop their prescribed blood pressure-lowering medications. No difference was found in functional outcome as assessed using ordinal logistic regression of the mRS at 90 days between the treatment and control groups. At 90 days, those allocated to continue anti-hypertensives had higher rates of major disability (Barthel Index $<60)(p=0.031)$ and worse cognitive outcome. One of the possible mechanisms stated by the authors is the higher rate of pneumonia in the group that continued antihypertensive medications, possibly due to aspiration of the medication. In addition, there was significant crossover; only $65 \%$ of the patients assigned to continue antihypertensives did in fact continue these medications. The authors conclude that it is reasonable to withhold antihypertensives in the setting of acute stroke until patients are neurologically stable and have appropriate oral/enteral access.

Also examining a timeframe of 1-week post-infarction, the SCAST trial assigned 2029 patients to candesartan or placebo for 7 days following ischemic or hemorrhagic infarct. ${ }^{15}$ This demonstrated that the use of candesartan in the days after infarct had little meaningful effect on recurrent stroke, myocardial infarction, vascular death or long-term functional outcome measured at 6 months. ${ }^{15}$ These results refute the findings of an earlier smaller industry-sponsored study called ACCESS, which included 342 patients randomized to candesartan therapy or placebo for 7 days post-infarction. ${ }^{16}$ Interestingly, there was no significant difference in blood 
Table 1: Key randomized controlled trials of blood pressure management in acute ischemic stroke

\begin{tabular}{|c|c|c|c|c|c|c|c|c|c|c|c|}
\hline Study (year) & $\begin{array}{l}\text { Total } \\
\text { study } \\
\text { pop }\end{array}$ & $\begin{array}{l}\text { Mean } \\
\text { age } \\
\text { (year) }\end{array}$ & $\begin{array}{l}\text { Stroke } \\
\text { severity } \\
\text { at onset }\end{array}$ & $\begin{array}{l}\text { Mean } \\
\text { time } \\
\text { to tx } \\
\text { (hours) }\end{array}$ & $\begin{array}{l}\text { Mean initial } \\
\text { BP }\end{array}$ & $\begin{array}{l}\text { Treatment } \\
\text { duration }\end{array}$ & $\begin{array}{l}\text { Mean BP at } \\
\text { treatment end }\end{array}$ & $\begin{array}{l}\text { Mean BP } \\
\text { difference } \\
\text { between } \\
\text { groups }(\mathrm{mm} \mathrm{Hg})\end{array}$ & $\begin{array}{l}\text { Primary } \\
\text { outcome } \\
\text { measures }\end{array}$ & $\begin{array}{l}\text { Follow-up } \\
\text { Duration }\end{array}$ & Results \\
\hline $\begin{array}{l}\text { COSSACS }^{12} \\
(2010)\end{array}$ & 763 & 74 & $\begin{array}{l}\text { NIHSS } \\
4\end{array}$ & 23.6 & $\begin{array}{l}\text { tx: } 149 / 80 \\
\text { cn: } 150 / 81\end{array}$ & 14 days & $\begin{array}{l}\text { tx: } 140 / 76 \\
\text { cn: } 153 / 84\end{array}$ & $\begin{array}{l}\text { Systolic: -13 } \\
\text { Diastolic: }-8\end{array}$ & $\begin{array}{l}\text { Death or } \\
\text { dependency } \\
(\mathrm{mRS}>3)\end{array}$ & 14 days & $\begin{array}{l}\text { No difference } \\
\text { (RR 0.86, 95\% Cl } \\
0.65-1.14 ; p=0.3 \text { ) }\end{array}$ \\
\hline $\begin{array}{l}\text { CATIS }^{13} \\
(2014)\end{array}$ & 4071 & 62 & $\begin{array}{l}\text { NIHSS } \\
4\end{array}$ & 15.3 & $\begin{array}{l}\text { tx: } 166.7 / 96.8 \\
\text { cn: } 165.6 / 96.5\end{array}$ & $\begin{array}{l}14 \text { days or } \\
\text { hospital } \\
\text { discharge (if } \\
<14 \text { days) }\end{array}$ & $\begin{array}{l}\text { tx: } 135.2 / 81.4 \\
\text { cn: } 143.7 / 85.3\end{array}$ & $\begin{array}{l}\text { Systolic: }-8.6 \\
\text { Diastolic }-3.9\end{array}$ & $\begin{array}{l}\text { Death or } \\
\text { dependency } \\
(\mathrm{mRS} \geq 3)\end{array}$ & $\begin{array}{l}14 \text { days or } \\
\text { hospital } \\
\text { discharge (if } \\
<14 \text { days) }\end{array}$ & $\begin{array}{l}\text { No difference (OR } \\
1.00,95 \% \mathrm{Cl} 0.88 \text { to } \\
1.14 ; p=0.98)\end{array}$ \\
\hline $\begin{array}{l}\text { SCAST }^{15} \\
(2011)\end{array}$ & 2029 & 71 & $\begin{array}{l}\text { SSS } \\
\text { tx: } 40.6 \\
\text { cn } 40.5\end{array}$ & 17.6 & $\begin{array}{l}\text { tx: } 171.2 / 90.3 \\
\text { cn: } 171.6 / 90.6\end{array}$ & 7 days & $\begin{array}{l}\text { tx: } 147 / 82 \\
\text { cn: } 152 / 84\end{array}$ & $\begin{array}{l}\text { Systolic: -5 } \\
\text { Diastolic: -2 }\end{array}$ & $\begin{array}{l}\text { Vascular } \\
\text { death, } \\
\text { stroke, Ml }\end{array}$ & 6 months & $\begin{array}{l}\text { No difference } \\
\text { (HR 1.09, 95\% Cl } \\
0.84-1.41 ; \mathrm{p}=0.53 \text { ) }\end{array}$ \\
\hline $\begin{array}{l}\text { ACCESS }^{16} \\
(2003)\end{array}$ & 342 & 68 & $\begin{array}{l}\text { Bl } \\
\text { tx } 60 \\
\text { cn: } 64.1\end{array}$ & 29.9 & $\begin{array}{l}\text { tx: 196/103 } \\
\text { cn: 199/102 }\end{array}$ & 7 days & $\begin{array}{l}\text { Mean BP range } \\
\text { over } 7 \text { days } \\
(160-200) / \\
(80-105)^{*}\end{array}$ & $\begin{array}{l}\text { No significant } \\
\text { difference } \\
\text { between } \\
\text { groups* }\end{array}$ & $\begin{array}{l}\text { Barthel } \\
\text { Index }\end{array}$ & 3 months & No difference \\
\hline $\begin{array}{l}\text { ENOS }^{14} \\
\text { glyceryl } \\
\text { trinitrate vs } \\
\text { cn (2015) }\end{array}$ & 4011 & 70 & $\begin{array}{l}\text { SSS } 34 \\
\text { NIHSS } \\
11\end{array}$ & $26 \bullet$ & $\begin{array}{l}\text { tx: } 167 / 90 \\
\text { cn: } 167 / 89\end{array}$ & 7 days & $\begin{array}{l}\text { tx: } 150.2 / 82.9 \\
\text { cn: } 151.3 / 84\end{array}$ & $\begin{array}{l}\text { No significant } \\
\text { difference at } \\
\text { day } 7\end{array}$ & mRS & 3 months & $\begin{array}{l}\text { No difference } \\
\text { (OR 1.01, 95\% Cl } \\
0.91-1.13 ; \mathrm{p}=0.83 \text { ) }\end{array}$ \\
\hline $\begin{array}{l}\text { ENOS }^{14} \\
\text { continue vs } \\
\text { stop (2015) }\end{array}$ & 2097 & 73 & $\begin{array}{l}\text { SSS } \\
\text { tx: } 32 \\
\text { cn } 33 \\
\text { NIHSS } \\
\text { tx } 12 \\
\text { cn } 11\end{array}$ & $26 \bullet$ & $\begin{array}{l}\text { tx: } 166 / 88 \\
\text { cn: } 168 / 89\end{array}$ & 7 days & $\begin{array}{l}\text { tx: } 145.6 / 80 \\
\text { cn: } 155.1 / 85.1\end{array}$ & $\begin{array}{l}\text { Systolic: -9.5 } \\
\text { Diastolic: -5.1 }\end{array}$ & mRS & 3 months & $\begin{array}{l}\text { No difference } \\
\text { (OR 1.05, 95\% Cl } \\
0.90-1.22 ; \mathrm{p}=0.55)\end{array}$ \\
\hline
\end{tabular}

pressure between treatment arms throughout the 7 day monitoring period, nor at 12 months follow-up. Results showed nearly double the rate of vascular events in placebo (18.7\%) compared with treatment (9.8\%) at 12 months $(p=0.026)$, which was a secondary endpoint. ${ }^{16}$

It is worth noting that within each of these trials the mean systolic blood pressure measurements varied minimally between experimental and control arms (Table 1), perhaps limiting measurable effects. ${ }^{12-16}$ COSSACS, CATIS, and SCAST demonstrated effective randomization, but did not analyze outcome measures by stroke subtype (i.e. lacunar, embolic, thrombotic), even though this distinction may be important. When compared to cardioembolic infarcts, lacunar strokes have been shown to present with higher blood pressure on admission as well as higher pressure six days from stroke onset. ${ }^{17-19}$ Future research should examine the relative effects of blood pressure variation specific to stroke subtypes.

The COSSACS and CATIS trials excluded all tissue plasminogen activator (tPA) cases, whereas participants receiving tPA were a minor demographic in SCAST (8\% of experimental and $9 \%$ of placebo) and ENOS (10-12\% within each of the four groups). This, however, should be taken into context of the fact that only an estimated $5.8 \%$ of all ischemic stroke patients receive intravenous (IV) tPA. ${ }^{20}$ Of greater relevance is that randomization to therapy occurred many hours and sometimes days after stroke onset within each of these trials. The benefits of moderate blood pressure control may be more pronounced in the immediate hours after stroke; however, in the CATIS trial there was a statistically significant difference in good outcome when considering patients who were randomized to antihypertensive therapy started greater than 24 hours after acute infarction. ${ }^{13}$ Another important consideration that is not accounted for by several of these large clinical trials is the care of the individual patient who displays worsening neurological symptoms with reduction of blood pressure due to a flow limiting stenosis of a large vessel. These patients require close observation with invasive continuous blood pressure monitoring and typically require a higher blood pressure target until the lesion is addressed.

In summary, the data from these RCTs is chiefly applicable to those patients with mild to moderate ischemic infarcts who do not receive thrombolytics, and who present without hypertensive urgency. There is no clear advantage to candesartan that should warrant specific selection of this medication for blood pressure management in acute stroke. Since the current literature shows no clear benefit of treatment of hypertension in the acute and subacute period and potential harm, as demonstrated by the ENOS trial, ${ }^{14}$ it is imperative that the clinician take into consideration the individual's medical and neurological status prior to targeting normotension. It is reasonable to withhold outpatient antihypertensive medications, except beta blockers, which should be decreased by $50 \%$ to prevent withdrawal tachycardia, during the acute period after an ischemic stroke. 


\section{Glycemic control}

Hyperglycemia during acute ischemic infarction may impair recanalization, contribute to cerebral edema, and increase likelihood of hemorrhagic transformation..$^{21,22}$ There is little evidence, however, to guide appropriate targets for blood glucose control in the acute and subacute management of ischemic infarction. The $140-180 \mathrm{mg} / \mathrm{dL}$ range proposed by AHA/ ASA guidelines is not specific to stroke patients, but instead reinforces findings from the NICE-SUGAR trial (intensive versus conventional glucose control in critically ill patients), which showed that liberalized targets of blood glucose (up to $180 \mathrm{mg} / \mathrm{dL}$ ) conferred mortality benefits in intensive care unit (ICU) patients. ${ }^{23}$

The 2007 GIST-UK trial enrolled 933 patients and showed no significant difference in rates of death or 90 day functional outcome (measured by Barthel index and mRS) between stroke patients randomized to continuous insulin versus saline infusion in the first 24 hours of hospitalization. ${ }^{24}$ The target range of plasma glucose in the intervention group was 4.6 to 8.0 mmol/L (or approximately 80-145 mg/dL). There was no prescribed glucose range for the placebo group.

The GIST-UK trial likely showed neutrality in treatment paradigms because of overall similarity in blood glucose measurements between groups; though statistically significant, the absolute difference in blood glucose between groups was only $0.57 \mathrm{mmol} / \mathrm{L}$, or approximately $10 \mathrm{mg} / \mathrm{dL}$. Moreover, the trial selected for patients with a history of well-controlled diabetes. Insulin-dependent diabetics were excluded from participation and mean glycated hemoglobin $\left(\mathrm{HbA}_{1 \mathrm{c}}\right)$ was low in both groups $(6.1 \%$ in treatment and $6.0 \%$ in placebo). ${ }^{24}$

Another trial of continuous insulin in stroke populations was GRASP, which showed a wider difference in blood glucose between treatment arms than the GIST-UK trial, but was limited by lack of statistical power (only 74 total patients enrolled). ${ }^{25}$ GRASP involved the following three groups: standard care (subcutaneous insulin treatment for target glucose range of 70 to $300 \mathrm{mg} / \mathrm{dL}$ ), tight control (continuous insulin therapy for range of $70-110 \mathrm{mg} / \mathrm{dL}$ ), and loose control (continuous insulin therapy for range of $70-200 \mathrm{mg} / \mathrm{dL}$ ). From a qualitative perspective, the GRASP trial showed relative safety (i.e. avoidance of severe hypoglycemia) of implementing IV insulin therapy in the setting of acute stroke, however it provides little guidance in regards to the relative benefits of tight glycemic control. Several small studies have correlated acute hyperglycemia with subsequent increase in volume of ischemic infarction. ${ }^{26-28}$ On the contrary, a larger study of 180 patients comparing IV insulin infusion with subcutaneous therapy demonstrated an increased infarct growth of $17.1 \mathrm{~cm}^{3}(p=0.04)$ for those assigned to intensive IV insulin with a significantly lower average 24-hour blood glucose. ${ }^{29}$ Future randomized trials should address the specific interplay between different blood glucose targets and the evolution of ischemic infarction, and functional outcomes.

Currently the SHINE trial (Stroke Hyperglycemia Insulin Network Effort) is recruiting a goal of 1400 patients for a randomized, blinded trial of subcutaneous versus IV insulin, with blood glucose targets of $80-130 \mathrm{mg} / \mathrm{dL}$ for the infusion group and 80-179 mg/dL for the placebo group. Outcomes will be based on 90-day mRS analyzed in the context of presentation NIHSS score. ${ }^{30}$ SHINE will no doubt add to the dialogue about glucose management strategies, however, the nuances of insulin protocols (i.e. IV versus subcutaneous insulin) should not overshadow the need for more research on the pathophysiology of hyperglycemia in acute ischemic stroke.

There is a paucity of evidence to guide glycemic control strategies for acute ischemic stroke patients with poorly controlled diabetes, as these patients were not well represented in study populations. For those patients without diabetes or with well-controlled diabetes, the data does not support enough benefit of IV insulin to justify the higher level of nursing care required for continuous insulin protocols in acute ischemic infarction. Though ischemic stroke patients (diabetic and non-diabetic alike) typically present with hyperglycemia, they should be monitored closely to avoid severe hypoglycemic episodes, which carries immediate threats to the brain and even long-term cerebral injury. ${ }^{11}$ Liberalizing blood glucose goals in order to prevent episodes of severe hypoglycemia is reasonable. More research is clearly needed to provide evidence regarding the optimal blood glucose targets for patients with acute ischemic stroke.

\section{Conclusions}

In this review article we discussed the management of temperature, blood pressure, and glycemic control in patients with subacute ischemic stroke. The current evidence supporting decision making for these common issues is limited and at times conflicting. Currently it is advisable to not perform therapeutic hypothermia for acute ischemic stroke patients until results from key trials support this practice. The common practice of allowing permissive hypertension for patients with acute ischemic stroke during the subacute period is supported by the literature. Following this time period it is reasonable to aim for normotension. Lastly in terms of glycemic control, extremes at both ends of the spectrum are to be avoided without a clear optimal target range. We have drawn attention to key upcoming clinical trials that may have an impact on the current recommendations for the management of these issues. It is difficult to isolate the treatment effect for each of these interventions and it is likely that these variables are intertwined. A bundled approach that takes into consideration all of these variables needs to be studied. We highlighted the gaps in our current knowledge in the management of these common problems to show areas for future research. Undoubtedly, the results of key trials mentioned in this review will provide us with guidance and further questions. $\square$

\section{Trial names:}

ACCESS $=$ Acute candesartan cilexetil therapy in stroke survivors

CATIS = China antihypertensive trial in acute ischemic stroke

COSSACS = Continue or stop post-stroke antihypertensives collaborative study

ENOS = Efficacy of nitric oxide, with or without continuing antihypertensive treatment, for management of high blood pressure in acute stroke

GIST-UK = Glucose-potassium-insulin infusions in the management of post-stroke hyperglycemia: the UK glucose insulin in stroke trial

GRASP = Glucose regulation in acute stroke patients

EuroHYP-1 = European Multicentre, Randomised, Phase III Clinical Trial of Therapeutic Hypothermia Plus Best Medical Treatment Versus Best Medical Treatment Alone for Acute Ischaemic Stroke

ICTUS 2/3 = Phase 2/3 Study of Intravenous Thrombolysis and Hypothermia for Acute Treatment of Ischemic Stroke

NICE-SUGAR = Normoglycemia in Intensive Care Evaluation and Surviving Using Glucose Algorithm Regulation

SCAST = Scandinavian angiotensin receptor blocker candesartan for treatment of acute stroke

SHINE = Stroke Hyperglycemia Insulin Network Effort 
1. Castillo J, Davalos A, Marrugat J, Noya M, Timing for fever-related brain damage in acute ischemic stroke, Stroke, 1998;29:2455-60.

2. Ntaios G, Dziedzic T, Michel P, et al., European stroke organisation (ESO) guidelines for the management of temperature in patients with acute ischemic stroke, Int I Stroke, 2015:10:941-9.

3. Hypothermia after Cardiac Arrest Study Group, Mild therapeutic hypothermia to improve the neurologic outcome after cardiac arrest, N Eng/ J Med, 2002;346:549-56.

4. Bernard SA, Gray TW, Buist MD, et al., Treatment of comatose survivors of out-of-hospital cardiac arrest with induced hypothermia, N Engl J Med, 2002;346:557-63.

5. Nielsen N, Wetterslev J, Cronberg T, et al., Targeted temperature management at 33 degrees $\mathrm{C}$ versus 36 degrees $\mathrm{C}$ after cardiac arrest, N Eng/ J Med, 2013;369:2197-206.

6. van der Worp HB, Macleod MR, Bath PM, et al., EuroHYP-1: European multicenter, randomized, phase III clinical trial of therapeutic hypothermia plus best medical treatment vs. best medical treatment alone for acute ischemic stroke, Int I Stroke, 2014;9:642-5.

7. Lyden PD, Hemmen TM, Grotta J, et al., Endovascular therapeutic hypothermia for acute ischemic stroke: ICTuS 2/3 protocol, Int J Stroke, 2014:9:117-25.

8. Sharma VK, Elevated blood pressure in acute ischemic stroke treat or leave?, Cerebrovasc Dis, 2016;41:101-2.

9. Willmot M, Leonardi-Bee J, Bath PM, High blood pressure in acute stroke and subsequent outcome: A systematic review, Hypertension, 2004;43:18-24.

10. Alqadri SL, Sreenivasan V, Qureshi Al, Acute hypertensive response management in patients with acute stroke, Curr Cardiol Rep, 2013:15:426.

11. Jauch $E C$, Saver $J L$, Adams $H P, J r$, et al., Guidelines for the early management of patients with acute ischemic stroke: A guideline for healthcare professionals from the american heart association/ american stroke association, Stroke, 2013;44:870-947.
12. Robinson TG, Potter JF, Ford GA, et al., Effects of antihypertensive treatment after acute stroke in the continue or stop post-stroke antihypertensives collaborative study (COSSACS): A prospective randomised, open, blinded-endpoint trial, Lancet Neurol, 2010;9:767-75.

13. He J, Zhang $Y, X U T$, et al., Effects of immediate blood pressure reduction on death and major disability in patients with acute ischemic stroke: The CATIS randomized clinical trial, JAMA, 2014;311:479-89

14. ENOS Trial Investigators, Bath PM, Woodhouse L, et al., Efficacy of nitric oxide, with or without continuing antihypertensive treatment, for management of high blood pressure in acute stroke (ENOS): A partial-factorial randomised controlled trial, Lancet, 2015:385:617-28.

15. Sandset EC, Bath PM, Boysen G, et al., The angiotensin-receptor blocker candesartan for treatment of acute stroke (SCAST): A randomised, placebo-controlled, double-blind trial, Lancet, 2011;377:741-50.

16. Schrader J, Luders S, Kulschewski A, et al., The ACCESS study: Evaluation of acute candesartan cilexetil therapy in stroke survivors, Stroke, 2003:34:1699-703

17. Toyoda K, Okada Y, Fujimoto S, et al., Blood pressure changes during the initial week after different subtypes of ischemic stroke Stroke, 2006;37:2637-9.

18. Fischer $\mathrm{U}$, Rothwell PM, Blood pressure management in acute stroke: Does the scandinavian candesartan acute stroke trial (SCAST) resolve all of the unanswered questions?, Stroke, 2011;42:2995-8.

19. Wang $Y, X u J$, Zhao $X$, et al., Association of hypertension with stroke recurrence depends on ischemic stroke subtype, Stroke, 2013:44:1232-7.

20. Saver JL, Fonarow GC, Smith EE, et al., Time to treatment with intravenous tissue plasminogen activator and outcome from acute ischemic stroke, JAMA, 2013;309:2480-8.
21. Bruno A, Liebeskind D, Hao Q, Raychev R, UCLA Stroke Investigators. Diabetes mellitus, acute hyperglycemia, and ischemic stroke, Curr Treat Options Neurol, 2010;12:492-503.

22. Kruyt ND, Biessels GJ, Devries $J H$, Ros YB, Hyperglycemia in acute ischemic stroke: Pathophysiology and clinical management, Nat Rev Neurol, 2010;6:145-55.

23. NICE-SUGAR Study Investigators, Finfer $S$, Chittock DR, et al., Intensive versus conventional glucose control in critically ill patients, N Eng/ J Med, 2009;360:1283-97.

24. Gray CS, Hildreth AJ, Sandercock PA, et al., Glucosepotassium-insulin infusions in the management of post-stroke hyperglycaemia: The UK glucose insulin in stroke trial (GIST-UK), Lancet Neurol, 2007;6:397-406.

25. Johnston KC, Hall CE, Kissela BM, et al., GRASP Investigators Glucose regulation in acute stroke patients (GRASP) trial: A randomized pilot trial, Stroke, 2009;40:3804-9.

26. Baird TA, Parsons MW, Phan T, et al., Persistent poststroke hyperglycemia is independently associated with infarct expansion and worse clinical outcome, Stroke, 2003;34:2208-14.

27. Els T, Klisch J, Orszagh M, et al., Hyperglycemia in patients with focal cerebral ischemia after intravenous thrombolysis: Influence on clinical outcome and infarct size, Cerebrovasc Dis, 2002;13:89-94.

28. Parsons MW, Barber PA, Desmond PM, et al., Acute hyperglycemia adversely affects stroke outcome: A magnetic resonance imaging and spectroscopy study, Ann Neurol, 2002;52:20-8.

29. Rosso C, Corvol JC, Pires $\mathrm{C}$, et al., Intensive versus subcutaneous insulin in patients with hyperacute stroke: Results from the randomized INSULINFARCT trial, Stroke, 2012;43:2343-9.

30. Connor JT, Broglio KR, Durkalski V, et al., The stroke hyperglycemia insulin network effort (SHINE) trial: An adaptive trial design case study, Trials, 2015;16:72. 